\title{
CPCSEA National Conference, India
}

\author{
Chennai, India, March 1-2, 2011
}

The Third National Conference of the Committee for the Purpose of Control and Supervision of Experiments on Animals (CPCSEA) was held on March 1-2, 2011 at the Breeze Hotel, Chennai. CPCSEA is the statutory body that oversees the welfare of laboratory animals under the Animal Welfare Division of the Ministry of Environment and Forests, Government of India. The aim of the conference was to focus on the recent norms and guidelines of CPCSEA and to provide a platform for CPCSEA representatives in institutions, universities and other members of the Institutional Animal Ethics Committees (IAEC) to interact and share their views with CPCSEA national committee members. The conference was organized by Mr. Anjani Kumar (Member Secretary, CPCSEA), Dr. P. Balakrishna Murthy (Director, International Institute of Biotechnology and Toxicology, Padappai), Dr. Shiranee Pereira (Scientist, Indian Council of Agricultural Research (ICAR)), and Dr. K. Nachimuthu (Expert Consultant, CPCSEA, Chennai).

Mr. M. F. Farooqui IAS, Additional Secretary and Chairman of CPCSEA, introduced the objectives of the conference in his inaugural address, voicing his optimism that India will be one of the world's major economies by 2050 . Towards this goal, India should invest in science and technology, including pharmacology, microbiology, and information technology. To match the other big economies of the world, India should endeavor to match the concern these countries exhibit - for animals in general and for experimental animals in particular. Invoking the love for animals in the culture, ethos, and religious practices of India, and the sentiments expressed by Mahatma Gandhi about animals, Mr. Farooqui said India should be a leader in protecting experimental animals. While our ultimate goal should be to fully replace animal use in experiments, he stressed the need to be sensitive to the pain and suffering of experimental animals and to avoid this wherever possible. He also emphasized the need to end the use of animals in education.

Dr. R. Prabakaran, Vice-Chancellor, Tamil Nadu Veterinary and Animal Sciences University (TANUVAS), Chennai, spoke about the healing power of animals and the role pet animals play in clinical therapies. He observed that loving and caring for animals relieves stress and tension. The TANUVAS, he said, tries to motivate this love and care for animals by way of an online course on animal welfare.

At the inaugural session, all conference participants took the CPCSEA pledge, which reads as follows: "I pledge to protect and improve the natural environment, including plants, lakes, rivers, and wild life and have compassion for all living creatures. I pledge to make a difference to the stray animals on the streets and work towards giving them the love and care they deserve. I refuse to abuse and I will be the voice of the voiceless and work for the improvement and well-being of all animals."

Mr. Anjani Kumar, Director (Animal Welfare) and Member Secretary of CPCSEA, outlined the role of CPCSEA. Each institution or establishment dealing with experimental animals should have a CPCSEA-approved animal housing facility. Maintenance should follow CPCSEA norms, and animal care should be in accordance with the Breeding of and Experimentation on Animals (Control and Supervision) Rules (1998). All experiments and the well-being of the experimental animals should be monitored by Institutional Animal Ethics Committees (IAEC), which shall have eight members, one of whom shall be a CPCSEA nominee. The Committee will scrutinize each research proposal carefully and approve it only if the experiment is absolutely necessary. The number of animals approved shall be the bare minimum required to satisfy the statistical analysis. Wherever called for, the animal should be subjected to anesthesia/analgesia. Effort must be put into rehabilitating animals after an experiment, and if the health condition of the animal does not allow this, the animal must be euthanized as permitted in CPCSEA norms. The CPCSEA nominee in the IAEC is empowered to visit the animal house facility at any time, even without giving prior notice, and inspect the facility with special reference to the well-being of the animals. Institutions that fail to fulfill these requirements will be severely dealt with, he said, and the approval for animal experiments will be cancelled.

Speaking about "Evolution of breeding and rules for animal experimentation in India," Dr. Vasantha Muthuswamy (Former Deputy Director General of Indian Council for Medical Research, New Delhi), Member of CPCSEA, referred to the "Prevention of Cruelty to Animals Act" of 1960, amended in 1982, which provides for the prevention of cruelty to animals in general. Chapter 4 deals with experiments on animals. The CPCSEA, which was constituted to fulfill a requirement in this Act, issued the "Breeding of and Experiments on Animals (Control and Supervision) Rules, 1998," and has updated the rules regularly to safeguard the experimental animals, she said.

Dr. P. Balakrishna Murthy (Director, International Institute for Biotechnology and Toxicology), Member of CPCSEA, emphasized good laboratory practice in animal research relevant for drug, chemical, and biotech product testing. According to him, "adoption of GLP will reduce the role of the confounding factors that influence the validity of preclinical toxicity studies and, thus, provide ethically and humanely meaningful data to regulators to make candid decisions on risk assessment."

Dr. Shiranee Pereira (Scientist, ICAR), Member of CPCSEA, outlined the validated alternatives in regulatory test- 
ing. Explaining the basic tenets of the 3R's concept and the various practicable components of each $\mathrm{R}$, she emphasized the need for validation of the various alternatives by competent organizations and agencies such as ECVAM, ICCVAM, JacVAM, etc., prior to acceptance by regulatory authorities such as OECD, EPA, European Pharmacopoeia, etc. She listed the various validated alternatives, most of which are full replacements, as well as others that replace vertebrates with less sentient animals. She emphasized that these alternatives must be practiced in laboratories in India engaged in contract testing for companies in the USA, the EU, and other parts of the world if they are to comply with the relevant laws. Using these alternatives in basic biomedical research as well could help save millions of animals.

Dr. Pereira gave a talk on "The concept of the $4^{\text {th }} \mathrm{R}-$ Rehabilitation - Principles of the CPCSEA in the rehabilitation of large animals following experimentation." She said this concept arose from the Gandhian philosophy of "Ahimsa" and, in spirit, is a continuation of the three R's concept of Russell and Burch (1959). According to the CPCSEA guideline, "persons using experimental animals have a moral responsibility to the animals after their use, and investigators are responsible for the after-care and/or rehabilitation of animals post-experimentation." Thus, rehabilitation of experimental animals is a legal requirement in India today.

Addressing the topic "Role and responsibility of IAECs," Ms. Norma Alvarez, (Practicing Senior Counsel, High Court of Mumbai), Member of CPCSEA, elaborated upon the rationale for having a CPCSEA nominee, a veterinarian, a socially aware person, and a scientist from outside the institute, in addition to four local members in an IAEC. This Committee examines proposals for performing experiments on small animals and provides an independent, competent, and timely review of the ethics before commencement of a study. In addition, it regularly monitors ongoing studies. Experiments on larger animals are monitored directly by the CPCSEA. The respective committees consider i) purpose of the experiment and relevance; ii) use of animals of lesser sentience; iii) minimizing pain; iv) proper care of animals; and v) post-experimental care, with rehabilitation or euthanasia.

Dr. A. Jagannatha Rao (Ramanna Fellow, Indian Institute of Science, Bangalore), Member of CPCSEA, spoke on the need for experiments with large animals and the need for welfare measures. The use of large animals such as monkeys, dogs, sheep, and cats is inevitable, he said, considering the regulatory requirements to be met before a drug is approved for human application. This makes it all the more important to insure strict adherence to welfare measures. Dr. K. Venkaiah (Scientist, National Institute of Nutrition, Hyderabad), another member of CPCSEA, noted that proper design of the experiment and the most appropriate statistical treatment can greatly reduce animal use in regulatory and toxicity testing.

Prof. Mohammad A. Akbarsha, Gandhi-Gruber-Doerenkamp Chair and Director Mahatma Gandhi Doerenkamp Center (MGDC), summarized issues arising from the use of animals in education, research, and testing in his talk on "Alternatives in education and in vitro toxicology." He said "it is important that animal dissection be dropped from the curriculum and be replaced with exercises more relevant to the recent trends in the respective subjects - especially exercises that also provide prospective employment opportunities to the learners. In particular, ICT-based, user-friendly teaching devices with which one can learn anatomy, physiology, ecology, evolution, etc. more effectively should be prescribed in the curriculum to replace animal dissections," he said. Adoption of the Up-and-Down method of the OECD by India could greatly reduce the number of animals and the number of tests, he contends. In vitro and in silico approaches to chemical, pharmacological, and/or cosmetics testing and vaccinology not only would greatly reduce the use of animals but would supply more reliable and relevant information. In his opinion, "It is time for India to wake up in this respect and catch up with the international trend.

The real problem in India is that the regulatory authorities are varied and do not see eye to eye. For example, while the Wild Life Protection Act prohibits capture of frogs of Rana species from the wild, the use of frogs in medical, veterinary, pharmacy, and science education is still enforced. It is time that a coordinated committee consisting of representation from MCI, PCI, VCI, ICMR, CSIR, DBT, DST, Central Drugs Standard Control Organization, CPCSEA, and similar regulatory authorities be formed. This subject must be seriously deliberated so as to evolve a comprehensive national policy. Development of new alternatives, particularly digital, in vitro, and in silico, should be encouraged and supported. India needs to organize a national authority to validate alternative methods, in the manner of ICCVAM, ECVAM, JaCVAM, and KoCVAM."

According to Dr. Sashi Motilal (Associate Professor, Philosophy Department, Delhi University, Delhi), Member of CPCSEA, "the Object Model, which treats animals as mere objects of use and does not consider inhumane treatment as ethically wrong because the human species is considered a superior species, is to be rejected. The Rights Model, which ascribes rights to animals also is flawed, since it requires animals to be given the same moral status as humans, which is conceptually difficult to ascribe to them. The Respect for Nature Model, based on biocentrism, is the ethically correct model. This model relies on the principle of equal consideration of relevant interests of all concerned, according to which animals and humans have similar interests, such as avoidance of pain and suffering. This third model is a true reflection of the 3Rs concept."

Dr. S. R. Srinivasan, Dean, Faculty of Science, Madras Veterinary College, Chennai, emphasized the need to integrate animal welfare into veterinary education. Dr. R. Raveendran, Professor of Pharmacology, Jawaharlal Institute of Post Graduate Medical Education and Research, Pondicherry, in his address on "Alternatives to animals in pharmacological education," supported the replacement of animal experiments in 
the pharmacology under-graduate curriculum with alternatives such as digital alternatives, simulation experiments, mannequins, etc. He was apprehensive, however, about the introduction of alternatives into the post-graduate pharmacology curriculum, since the candidates qualifying in this program may enter the pharmaceutical industry, where animal experiments are necessary for regulatory approval. He insisted that the alternatives for pharmacology education should be made affordable and relevant to the special context of India.

According to Dr. S. Thilagar, Professor, Surgery, TANUVAS, Chennai, while several countries have started using alternatives to animals for training and experiments, there is resistance to this in India, particularly from teachers - even though published reports show that the use of alternatives rather than animals results in better learning outcomes. He spoke of opportunities to replace animal use in surgical training and veterinary studies. He suggested avoiding duplication of animal experiments by establishing an open source research bank.
The CPCSEA nominees of the IAECs held a free session to discuss their experiences IAEC members. Most of the issues raised involved non-adherence or misinterpretation of the CPCSEA guidelines. It was emphasized that the CPCSEA nominees in IAECs should be vigilant and strict but at the same time motivate the other members of the IAECs to adhere to the CPCESEA guidelines, which require implementation of the 4R's (Reduce, Refine, Replace, and Rehabilitate).

The MGDC distributed complimentary copies of the abridged version of Russell and Burch's "The Principles of Humane Experimental Techniques" (printed in India with kind courtesy of FRAME, UK), a Pro Dissector Frog CD, and a copy of a recent issue of ALTEX to the CPCSEA officials, members, and the participants.

Mohammad A. Akbarsha, Mohammad Zeeshan (MGDC, India) and Shiranee Pereira (ICAR, India) 